\title{
Thoreau's "Sounds" as Linguistic Dialectic and Cultural Critique
}

\section{Henrik Otterberg}

Gothenburg University

\begin{abstract}
This essay re-examines Thoreau's "Sounds" chapter in Walden (1854), traditionally read - by Leo Marx, John Carlos Rowe and others - as an amalgam of defiant rhetoric and quiet defeat in the face of encroaching technology made manifest in the invasion of the author's pond side idyll by the new railroad. Both these received conclusions are questioned in this article as I seek to challenge the prevailing view of Thoreau's putatively adamant faith in the powers of his own language, a critical position which obfuscates the larger meaning of Thoreau's practical surrender to technology in the face of circumstance.
\end{abstract}

Keywords: Thoreau - Walden - "Sounds" - railroad - technology - nature/culture divide-language crisis-dialectic.

It seems that a distinct if quiet consensus has emerged among Thoreau scholars of late. Regardless what they tend to make of Walden's narrator, and his relevant nearness or necessary distance from the historical Thoreau who assembled the book, scholars tend to posit a nearly absolute faith in Thoreau's ability to construct his own narrative. At least in a linguistic sense, then, Walden seems "Walled-in" to most if not all comers, to borrow one of its own manifest puns (183)'. In a 1995 study of Walden's genesis tracing its amplifications and evasions of primary journal material, Robert Milder describes the pervasive critical mood: readers often find themselves, Milder writes, “free but 'superintended.' /---/ We read the book according to our ingenuity, that is, but with a constant suspicion that whatever meaning we may generate has been anticipated by the writer whose air of commanding all conceivable

1. Quotes here and henceforth from the standard edition of Walden, ed. J. Lyndon Shanley (Princeton: Princeton University Press, 1971). 
linguistic traces of a word leads us, even in the delight of our invention, to marvel at his orchestration of this wondrous game."

Characteristically, however, what is seen as strength in one account invites charges of weakness in another. John Carlos Rowe, for example, has argued that "Thoreau may employ language in Walden more cleverly than in any of his other works, but he scrupulously avoids the problematic of language itself," as if "the natural facts were sufficient for the grammar of our lives."3 This statement echoes, if with some irony, the familiar transcendentalist notion that natural facts, when properly perceived, will yield higher truths; the necessary faculty - beyond basic Understanding - being Reason, a realm of divine intuition kindled in the mind of deliberate and discerning seekers. Yet Rowe's secularized critique is only one in a spectrum. Sharon Cameron has argued from a deconstructive vantage that while Thoreau's Journal represents an extreme attempt to render the "natural" - what she calls "a passion for nature divorced from social meaning" - Walden succumbs precisely to the "social" and accommodated, "civiliz[ing]" and "represent[ing]" nature in ... [conventional] forms that are receptive to it". ${ }^{4}$

While I would take issue with Rowe's and Cameron's sweeping conclusions, I find the core questions they raise regarding the status of language as a mediator between nature and culture in Thoreau's written work compelling. Yet given the ample self-reflective and self-deflective qualities of the Walden narrator, ought we not to expect some internal debate on the potential of language in Thoreau's book?

Among the many discourses of dissent in Walden, one of the more familiar is the narrator's diatribe against the railroad and its iron horse in the "Sounds" chapter, seminally discussed by Leo Marx in The Machine in the Garden. Thoreau's critique of overt technology culminates defensively, in Marx's reading: by "restoring the pastoral hope to its traditional location ... [Thoreau] removes it from history, where it is manifestly unrealizable, and relocates it in literature, which is to say, in his own consciousness, in his craft, in Walden." ${ }^{5}$ But does

2. Robert Milder, Reimagining Thoreau (Cambridge: Cambridge University Press, 1995), p. 79.

3. See Rowe's essay "The Being of Language: The Language of Being" in Henry David Thoreau: Modern Critical Views, ed. Harold Bloom (New York \& Philadelphia: Chelsea House Publishers), 1987, pp. 145-171 (147).

4. See Cameron's Writing Nature: Henry Thoreau's Journal (Chicago \& London: University of Chicago Press, 1985), p. $23 \mathrm{f}$.

5. See L. Marx The Machine in the Garden: Technology and the Pastoral Ideal in America (London, Oxford \& New York: Oxford University Press, 1964), p. 265. 
Thoreau really give away as much ground as Marx proposes? Another reading would suggest that the railroad poses a more fundamental threat to Thoreau than its physical apparitions alone would imply, ultimately hinting of the incursions of writing itself in seeking to capture and convey valuable aspects of nature. Nonetheless Thoreau does not concede his redemptive project, which beneath its spiritual thrust involves a reconciling of culture with nature and of writing with its chosen object(ive)s.

In a basic sense, Thoreau not only seeks what we might call the finer fruits of nature in Walden, but also situates himself as a representative of culture. Etymologically, culture begins with cultivation, with man's settlement and tilling of the soil, transforming the soil's output - in the present case making it "say beans" instead of wormwood, piper and millet grass (157). This is of course an interesting opening, for what status could the resulting patch of "middle landscape" in Marx's sense have to the mind of a transcendentalist? Thoreau describes his own bean-field as "half-cultivated," and implies that he ultimately worked it for the sake of "tropes and expression, to serve a parable-maker one day" (162). But what could such a hybrid field - brought forth as it were by mere human understanding - hope to yield as compared to a soft-treading interaction with wild nature, supposedly the mother-lode of transcendentalist reason?

Let us turn to the introduction of the "Sounds" chapter of Walden, with these questions in mind. Here Thoreau warns us that "while we are confined to books/.../ we are in danger of forgetting the language which all things and events speak without metaphor, which alone is copious and standard. Much is published, but little printed. The rays which stream through the shutter will be no longer remembered when the shutter is wholly removed. What is a course of history, or philosophy, or poetry, no matter how well selected, or the best society, or the most admirable routine of life, compared with the discipline of looking always at what is to be seen? Will you be a reader, a student merely, or a seer?" (111).

This is not as naive a statement as it may first appear. Thoreau begins by making clear that language (as reconstructed experience) necessarily involves confinement. Language thus proves a shutter to the light of reality, though actually the narrator is elsewhere keen to inform the reader that his actual pond-side house had no blinds or curtains for its part.

But of course Thoreau realizes that his writing, in an absolute sense, must fail. To capture and "print" without human clutter nature's wealth of "published" expressions is patently impossible. To (re)create a world, one must either be a 
god or artist of kouros with unlimited time at one's hands. What "Sounds" does is rather to enact a dialectic on the human possibilities of writing.

The second paragraph of the chapter reads optimistically. "There were times," the writer says, "when I could not afford to sacrifice the bloom of the present moment to any work, whether of the head or hands" (111). This echoes his exhortation in "Economy," where he tells us that "[m]ost men, even in this comparatively free country, through mere ignorance and mistake, are so occupied with the factitious cares and superfluously coarse labors of life that its finer fruits cannot be plucked by them," adding that "[t]he finest qualities of our nature, like the bloom on fruits, can be preserved only by the most delicate handling" (6).

As related to his work, these statements inform us that writing, while inevitably residual, must be crafted with the utmost care. Bloom - as we shall seeis what writing strives to capture, yet it is bound to tarnish. Read in this light, Thoreau's ensuing report that "it was morning, and lo, now it is evening, and nothing memorable is accomplished" (112) at once delineates the chapter's temporal structure and ironically concedes to its shortcomings - stocked with a 'soiling' metaphor as it is.

Thoreau's next move is to illustrate his attempt at a clean slate in physical terms. This action reifies his earlier rhetorical call for a solid pivot or "point d'appui" for his writing:

When my floor was dirty, I rose early, [and set] all my furniture out of doors... It was pleasing to see my whole household effects out on the grass, making a little pile like a gypsy's pack, and my three-legged table, from which I did not remove the books and pen and ink, standing amid the pines and hickories. They seemed glad to get out themselves, and as if unwilling to be brought in. I was sometimes tempted to stretch an awning over them and take my seat there. It was worth the while to see the sun shine on these things, and hear the free wind blow on them; so much more interesting most familiar objects look out of doors than in the house. A bird sits on the next bough, lifeeverlasting grows under the table, and blackberry vines run round its legs; pine cones, chestnut burs, and strawberry leaves are strewn about. It looked as if this was the way these forms came to be transferred to our furniture, to tables, chairs, and bedsteads,because they once stood in their midst. (112-13)

Thoreau here stages the drama of his work as a still life. Symbolically clearing his page, he places his writing tools out of doors: to meet with the nature they are constantly struggling to grasp. Once placed there, it is hardly surprising to find them "unwilling" to return indoors. Thoreau enjoys seeing the sun play on their surfaces, and is yet aware that taking a seat with them is no 
real solution to his dilemma. Bound to civilization as he ineluctably is, the writer would blur the influence of nature; here, his awning blots out the sun in emulation of his house (which by its very existence marks a separation from the outdoors). ${ }^{6}$ Finally, fully conceding his fantasy, Thoreau bluntly denies his writing tools any favored link to nature. He does not list them among the various items that seem to have taken their form from having "stood in [nature's] midst."

Thoreau's next paragraph gives a description of the rich and varied vegetation about his house. At the same time, it gives resonance to his effort of writing in highlighting the vigorousness of nature. The sand cherry, its stems "weighed down with good sized and handsome berries, fell over in wreaths like rays on every side," Thoreau recalls. Further, sumac was "pushing up through the embankment," its leaf buds "suddenly pushing out late in the spring from dry sticks which had seemed to be dead, [and] developed themselves as if by magic into graceful green and tender boughs." In fact, Thoreau maintains, "so heedlessly did they grow and tax their weak joints" that he at times found a bough "broken off by its own weight." The nearby berries in turn often "bent down and broke their tender limbs" (114).

The dry stick which "had seemed to be dead" lends itself figuratively as the writer's pen. From Thoreau's vantage, he would feel it invigorated, indeed sprung to life, from nature's influence. But his pen cannot contain the immense pressure of life surrounding. The omnipresent bending and breaking in the paragraph signals Thoreau's concession that his art must yield also in this sense; he cannot get it all down, do everything justice. This echoes his concern in "Economy," where - as we have noted - he speaks of the difficulty of man's grasping the finer fruits of life, a feat made possible only by what he calls "the most delicate handling." "Yet," he continues, "we do not treat ourselves nor one another thus tenderly" (6).

Another aspect of the paragraph is significant. Nature is seen as "taxing [its] weak joints" in a process of maturation and expression; its very "weakness" allowing a unique and tender bloom soon succumbing to its own splendor. When Thoreau's stereotypical man, on the other hand, strives for another kind of florescence - of profit by trade or industry - the iron "joints" he constructs are made to hold indefinitely under tension. Thoreau reminds the reader in 
"Economy" of the steadily functioning "joints of the agricultural machine," and is also concerned over the incessant, semi-mechanical "activity of joint stocks and spades" that furthers the railroad $(33 ; 53)$. But these strong, manmade links are, as Thoreau wishes to assure us, trivial to him. While they are said to have "nothing important to communicate" (52), the business of the greening stem and swelling berry is the expression of life itself.

Yet Thoreau's crisis of writing in adequately communicating his understanding of nature is inevitably amplified by the very distinction between mechanical "joints" and tender blooms - a distinction which, in effect, begs the question of how his own language would perform. What kind of benevolent connection as opposed to mechanical "joint" can he aspire to establish with his pen? Granted nature's gracing him with a "green stem", can he still write nature? Or is he bound to a chain of supposedly lifeless communication with a "dry stick?" This seems to me a fundamental question posed by the "Sounds" chapter, and it is encapsulated by a significant passage describing the locomotive:

[W] hen I hear the iron horse make the hills echo with his snort like thunder, shaking the earth with his feet, and breathing fire and smoke from his nostrils, (what kind of winged horse or fiery dragon they will put into the new Mythology I don't know), it seems as if the earth had got a race now worthy to inhabit it. If all were as it seems, and men made the elements their servants for noble ends! (116)

What does the tantalizing "new Mythology" phrase signify? A modern reader will presumably first recognize the "winged horse" as an icon of progressiveness, speeding toward the supposedly bright future of a Commercial Age. Thoreau also mentions a "fiery dragon," yet we can still see this beast as a possible complement to Pegasus, emblematic of strength and assertiveness, or yet again as a Plutonian guardian of wealth accrued.

Another reading would see "the new Mythology" as a deft allusion to the contemporary practice of painting portraits of company magnates and mythological beasts on the flanks of locomotive engines and tenders: at once a tangible and metaphorical image characteristic of Thoreau's double entendre. But ultimately, of course, the locomotive image and its resonance in the present context will depend on the writer's attitudes toward his object. What could the engine and its variable guise in "the new Mythology" mean to him? The Journal in this case presents us with an interesting clue. In an entry of September 20, 1851, almost three years before the publication of Walden, Thoreau writes of a return from surveying: 
A fatal coarseness is the result of mixing in the trivial affairs of men. Though I have been associating even with the select men of this and the surrounding towns, I feel inexpressibly begrimmed, my pegasus has lost his wings, he has turned a reptile and gone on his belly. Such things are compatible only with a cheap and superficial life. The poet must keep himself unstained and aloof. Let him perambulate the bounds of Imagination's provinces the realms of faery, and not the insignificant boundaries of towns. ${ }^{7}$

This meditation on the poet's lot is a recurrent theme with Thoreau. He frequently portrays himself as Apollo tending the flocks of Admetus, doing base practical chores rather than truly living and writing. A metaphorical aspect of the passage, however, strikes the reader as novel: the stakes in the "pegasus" and "reptile" pairing are here directly personal. Pegasus, in this context, is most profitably understood as a favorite of the Muses, a sprightly token of inspiration. The reptile, however, would be the heavenly steed's diametrical opposite: dull, plodding, and coarse - connoting a wing-clipped inspiration or even the inability to write.

To read the cited passage with the Journal's Pegasus/reptile passage in mind entails understanding the beasts of "the new Mythology" as oppositional - an opposition which, at the same time, bears on the writer and his task as tensions of vocation. This in turn prompts us to ask further questions. Does the locomotive "they" are launching inspire (as associated with a "winged horse"), or merely drain sensibilities (being linked to a "reptile on its belly")?

This is an important query, for here is undeniably a serious problem looming behind the locomotive in "Sounds." To what extent, exactly, can it credibly be rendered as a natural fact? Colloquially called an "iron horse," it shifts uneasily between the natural and unnatural, the animate and inanimate. The locomotive's myth, as embellished upon by Thoreau in animate vein, is not fully convincing, does not succeed in integrating the railroad with the natural. Here we may fruitfully contrast him with Emerson, who adopted a position whereby human tcchnology was seen as continuous with natural creation: "Nature", Emerson once wrote, "adopts [our inventions] very fast into her vital circles, and the gliding train of cars she loves like her own."

What remains, then, for Thoreau if he refuses the facile yet encompassing

7. Quoted from The Writings of Henry David Thorean: Journal, Volume 4: 1851-1852, ed. Leonard N. Neufeldt et al. (Princeton: Princeton University Press, 1992), p. 85.

8. Quoted from G. Ferris Cronkhite, "The Transcendental Railroad" in the New England Quarterly 24 (1951), pp. 306-28 (314). 
gestures of Emerson? Is there any hope of reconciling nature and culture at this juncture? There is an intriguing allusion to the father in "Sounds" where the narrator describes the railroad in terms which may at first seem like recognition of his mentor's stance: "We live the steadier for it. We are all educated thus to be sons of Tell. The air is full of invisible bolts. Every path but your own is the path of fate. Keep on your own track, then" (118). Yet Thoreau's ambivalence is everywhere apparent. Are we to be archers of Tell's precision, trusting our weapons, or are we to be sons of Tell, continually exposed to the risk of imprecision in reaching for the goals of our fathers, in danger of being subordinated to the industry they have fostered? The bolts in the air may not simply be there to steady our lives, but to threaten them as well. Bolts forge our constructions, to be sure, but they also denote the end-pieces of our weapons, like that of Tell's. They are easily turned against us. The remedy of such risk is a step aside: away from mechanics, away from the common legacy of misdirected industry, and away from a naive trust in tools. To keep one's own track, in this regard, becomes a matter of freedom or fate, life or death.

"Sounds" turns next to an encounter with a freight train, where Thoreau finds himself enchanted at the sight of worn cloth: "This car-load of torn sails is more legible and interesting now than if they should be wrought into paper and printed books. Who can write so graphically the history of the storms they have weathered as these rents have done? They are proof-sheets which need no correction" (119). Clearly Thoreau stresses the superiority of direct experience. The sails themselves would give a more accurate log of their voyaging wear and tear than writing ever could. Toying further with the idea of flawless transmission, Thoreau muses that the cloth would serve truth in its proper guise; that on it we will find "written tales of real life, high and low, and founded on fact!" (120).

However Thoreau's next digression immediately puts such hopes in doubt. Passed by cars loaded with salted fish "thoroughly cured for this world," the narrator goes on to suggest that this fish - understood as a token and gift of nature - may be used for almost any purpose, until "at last [one] cannot tell surely whether it be animal, vegetable, or mineral" (120). In the end it comes out an "excellent dun fish for a Sunday's dinner," but that is arguably far from speaking its living experience and form. These are rather erased by human handling. Summing up his discussion of the cargo, Thoreau echoes his assertion on the fate of books in a commercial environment: "While these things go up other things come down" (121). His final observation comes to him as 
a personal message: he looks up from the leaves of his book to catch sight of their stately origin - a tall northern pine shuttled away on a cargo wagon. This serves him as a reminder of his authorial debt and obligation to nature.

Following the first freight train, Thoreau observes another one bearing cattle and sheep. This transport gives the impression of "a pastoral valley ... going by" and again illustrates Thoreau's awareness of the complexity of his chosen task (121f). As a writer, he would be a pastoral drover of sorts - seeking to escort his narrative to peaceful pasture in nature's midst. But his own text again denies the feasibility of such a scheme. The drovers are finding "their vocation gone," yet they still cling "to their useless sticks as their badge of office" (122). The remaining choice for the writer, as mirrored by the fate of the shepherd dogs, presents itself as one between the domestic and the wild. Either he may return to domesticity "in disgrace" as he writes of the dogs - and by implication to institutional society and its various trappings, or he may lose himself running wild "with the wolf and the fox," thus forfeiting his calling to communicate. "[T]he pastoral life," the hope of a reconciliation with nature, is to Thoreau here inexorably "whirled past and away."

Nevertheless, Thoreau has his insistences, his wish to explore new possibilities. He recalls the local town bells, whose chimes he claims produce a melody "worth importing into the wilderness." Heard from the pond their echo is further "to some extent ... an original sound. It is not merely a repetition of what was worth repeating in the bell, but partly the voice of the wood." And so there is once again hope, it seems, of détente between the wild and the civilized. As if to immediately reinforce this possibility, the writer humorously recalls having confused some youths' singing with "the cheap and natural music of the cow" at pasture: so much so, in fact, that the sounds finally seemed "one articulation of Nature" (123).

The passages that follow on owls and bullfrogs broaden and expound this newfangled idea. His humorous attempts to capture the sounds of these animals simultaneously play with the burden of metaphor and the lure of the pathetic fallacy. His owls, for instance, "take up [a] strain ... like mourning women their ancient u-lu-lu," being representative wailers for mankind - "Oh-O-O-Oo that I never had been bor-r-r-r-n!" (124f). True, Thoreau half-concedes the shortcomings of such anthropomorphism when he struggles to define "their gurgling melodiousness, - I find myself beginning with the letters gl when I try to imitate [them]," while he also transcribes the sounds onomatopoetically and recognizably as "-Hoo hoo hoo, hoorer hoo," thus indicating that the birds furnish a natural catharsis by doing "the idiotic and maniacal hooting 
for men" (125). But this does not exhaust the calls' significance. The owls also suggest "a vast and undeveloped nature which men have not recognized" (125), a distinction Thoreau sees fit to repeat in his closing paragraph on the nocturnal raptors. There is thus a persistent oscillation between the familiar (or familiarized) and the other in the owls' sound; between what can be rationalized and grasped in words, and what cannot.

The theme develops with Thoreau's portrayal of chanticleer, his cherished clarion bird. He praises its crowing alertness and adds that it was once a wild fowl in India. The question he now puts to us is if this bird "could be naturalized without being domesticated" (127)? In other words, could it, given its present circumstances, be de-domesticated to live a more natural life? And could then, by implication, Walden's writer also shed his shackles of domesticity and become re-enlivened in turn? His explicit project, after all, positions itself precisely alongside chanticleer's, as he is careful to inform us of with his introductory motto on Walden's title page. And a successful reorientation, we are presently told, would have the power of putting "nations on the alert," making them truly "healthy, wealthy, and wise" (127) in ways presumably not imagined by Benjamin Franklin.

Having gradually conceded to the domesticity of his language in the latter half of "Sounds," Thoreau increasingly realizes his task as one of re-naturalization. Appropriately enough, he informs us that he "kept neither dog, cat, cow, pig, nor hens, so that you would have said there was a deficiency of domestic sounds" around the house (127). And he describes his immediate environs as follows in concluding the chapter:

No yard! but unfenced Nature reaching up to your very sills. A young forest growing up under your windows, and wild sumachs and blackberry vines breaking through into your cellar; sturdy pitch-pines rubbing and creaking against the shingles for want of room, their roots reaching quite under the house. Instead of a scuttle or a blind blown off in the gale, -a pine tree snapped off or torn up by the roots behind your house for fuel. Instead of no path to the front-yard gate in the Great Snow, - no gate, -no frontyard, - and no path to the civilized world! (128)

The distinction between nature and dwelling is here deliberately blurred. Thoreau's final gesture in "Sounds" can hence be read as one of positive yielding. Boundaries are seemingly erased. Nature literally engulfs the house, and also, perhaps, its writer. Conspicuously, in this last paragraph Thoreau's "I" is omitted. Instead he gives us "Nature reaching up ... to your sills," 
vines "breaking into your cellar," and a pine falling "behind your house." The implication is that this experience is accessible to anyone. The writer has hinted at how it may be achieved, but up to now kept his account carefully personalized. Now at length as we read his chapter as a call to direct, unmediated experience - getting outdoors, perceiving natural sights, sounds, smells and indeed, if we return to his introduction in "Sounds" as a call not to forget nature's wealth of expression, we realize we may be unfair in judging Thoreau's writing by standards he rather reserves for perception as such.

Appropriately, in the beginning of "Sounds" Thoreau admits to chuckling for himself, to temporarily forsaking work, and to letting his life itself "hecome my amusement ... never [ceasing] to be novel" (112). This is a punning statement at once forming a representative hope, an admission of fictionalizing and, as all Thoreauvians will know, a joking gesture toward a sedulously upheld writing practice.

"Sounds" as a whole deserves to be read in light of similar self-recognition. Nothing could be simpler than to string its metaphors - its locomotives drumming like partridges or screaming like hawks, its melancholy owls, its glassy pond - like a noose around the writer's neck, pronouncing him guilty of hoax and false promises: Where is pure nature? Yet Thoreau has in fact left clues to the representational and ontological obstacles all along, while constantly testing the issue of his redemptive writing from new angles. True, as Leo Marx has stressed, Thoreau's famous Deep Cut epiphany in "Spring" - which along with the breaking of the pond's ice tangibly and metaphorically expresses Walden's message of hope - must be understood as imaginative: the myriad forms resembling bird's feet, leopard's paws, leaves, wings, lungs and bowels Thoreau describes oozing forth from the sun-baked railroad causeway are of course inanimate, not alive in any conventional sense. In similar vein one might feel compelled to add that Thoreau's program of reforming domesticated animals to wilder states, as sketched in "Sounds," remains a rhetorical gesture rather than practically undertaken task. But such objections turn a blind eye to the self-scrutinizing richness and complexity of Thoreau's text; the former by holding, as it were, that sculpture is merely stone. It would surely be more productive and evenhanded to say that Thoreau's interest in Walden proves to lie in what one can do with stone. Thoreau's familiar analysis of culture amounts to a critique of ossification and rigidness, of petty greed, superfluous wants and stagnant imaginations. It appears from Walden's meta-critical undercurrents discussed here that language for its part 
risks languishing in cliché, hackneyed phrases and commercial vapidity; that it too may "lose its nerve and degenerate into palaver wholly" (244). ${ }^{9}$ Yet Thoreau's plea in "Sounds" and elsewhere nevertheless retains its positive character. The writer and his reader must constantly explore boundaries and strive, as he puts it in pun, at once to effect and to understand the value of "Extra vagance!" (324). 